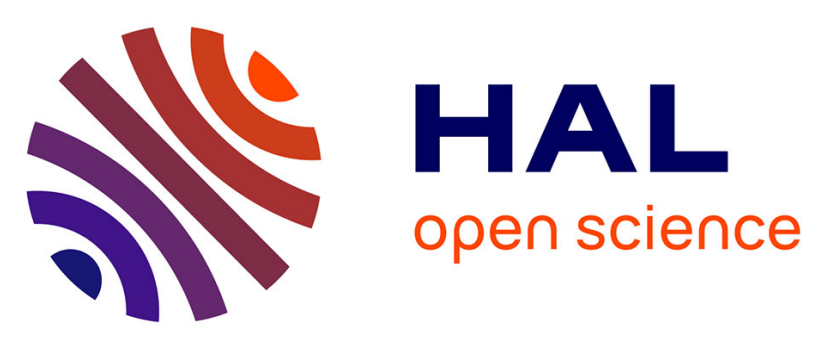

\title{
Uzbekistan Towards Industry 4.0. Defining the Gaps Between Current Manufacturing Systems and Industry 4.0
}

Ikrom Kambarov, Gianluca D'antonio, Khurshid Aliev, Paolo Chiabert, Jamshid Inoyatkhodjaev

\section{To cite this version:}

Ikrom Kambarov, Gianluca D'antonio, Khurshid Aliev, Paolo Chiabert, Jamshid Inoyatkhodjaev. Uzbekistan Towards Industry 4.0. Defining the Gaps Between Current Manufacturing Systems and Industry 4.0. 15th IFIP International Conference on Product Lifecycle Management (PLM), Jul 2018, Turin, Italy. pp.250-260, 10.1007/978-3-030-01614-2_23 . hal-02075564

\author{
HAL Id: hal-02075564 \\ https://hal.inria.fr/hal-02075564
}

Submitted on 21 Mar 2019

HAL is a multi-disciplinary open access archive for the deposit and dissemination of scientific research documents, whether they are published or not. The documents may come from teaching and research institutions in France or abroad, or from public or private research centers.
L'archive ouverte pluridisciplinaire HAL, est destinée au dépôt et à la diffusion de documents scientifiques de niveau recherche, publiés ou non, émanant des établissements d'enseignement et de recherche français ou étrangers, des laboratoires publics ou privés.

\section{(c)(1)}

Distributed under a Creative Commons Attribution| 4.0 International License 


\title{
Uzbekistan towards Industry 4.0. Defining the gaps between current manufacturing systems and Industry 4.0
}

\author{
Ikrom Kambarov, Gianluca D`Antonio ${ }^{2}$, Khurshid Aliev², \\ Paolo Chiabert ${ }^{2}$, Jamshid Inoyatkhodjaev ${ }^{1}$ \\ ${ }^{1}$ Turin Polytechnic University in Tashkent, Kichik Halqa Yuli 17, 100095 Tashkent, \\ Uzbekistan \\ ${ }^{2}$ Politecnico di Torino, corso Duca degli Abruzzi 24, 10129 Torino, Italy \\ \{ikrom.kambarov, j.inoyatkhodjaev\} @polito.uz \\ \{gianluca.dantonio, khurshid.aliev, paolo.chiabert\}@polito.it
}

\begin{abstract}
With the advancements in industry technology and applications, many concepts have emerged in manufacturing. Since the term Industry 4.0 was published to highlight a new industrial revolution, many manufacturing organizations and companies in Europe, North and South America are researching on this topic. Even the Industry 4.0 concept is included on government duty, sponsored by national initiatives and research funding. However, developing country like Uzbekistan, with high industrial potential are experiencing a different position and the technology roadmap of accomplishing Industry 4.0 is not clear yet. In the last 20 years, Uzbekistan managed to join the group of lower-middle income countries; the ultimate development goal of the country in the next stage is to reach the development benchmark comparable to the higher-middle income group by 2030. Therefore, this paper aims to depict the current state of manufacturing systems in Uzbekistan and identify the gaps with the Industry 4.0 requirements. The findings of this paper can serve for researches from emerging countries as technological roadmap towards Industry 4.0 paradigm and can assist industrial people in understanding and achieving the requirements of Industry 4.0.
\end{abstract}

Keywords: Industry 4.0, Manufacturing systems, Developing Countries.

\section{Introduction}

In the past three decades, there are significant development took place information technology in general. In order to compete and offer more value to the customers, developed countries started to apply advance technologies on production level. In USA and some other countries, such initiatives are termed as fourth industrial revolution, Internet of Things, or next generation systems. Whereas in Germany, it is driven by German government and referred as Industry 4.0 [1].

Industry 4.0 will change supply chains, business models and business processes significantly. However, researchers hold different opinions of the specific requirements of Industry 4.0 and its accomplishment, acting on their various industrial technology applications [11]. 
Industry has had an important role in the economic development of Uzbekistan. Since its independence in 1991, attraction of advanced technologies, foreign investments and modern management paradigms have been set as a priority policy of the government. In the last years, the industrial sector has shifted its focus from capitalintensive basic industries towards developing manufacturing sectors that produce goods of higher technological level and contribute more to the growth of productive employment, leading to an increased share of industry in GDP of the country.

According to investigations of the Center of Economic Research [2], the ultimate development goal for the Uzbekistan is to join the group of upper middle-income countries by 2030 . With this end in view, it is important to maintain stable economic growth

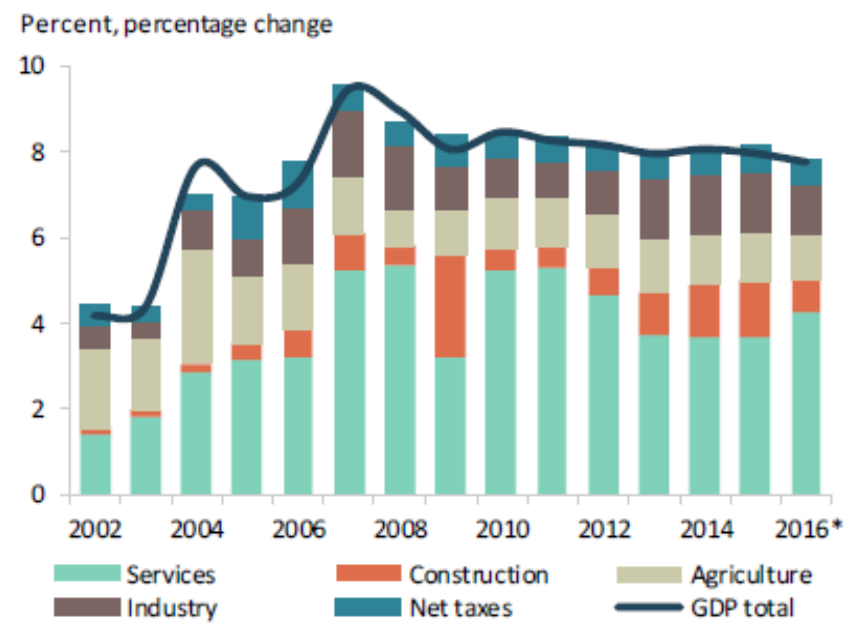

Fig. 1. Structural Changes in the Uzbek Economy over the Last Years, GDP structure [2].

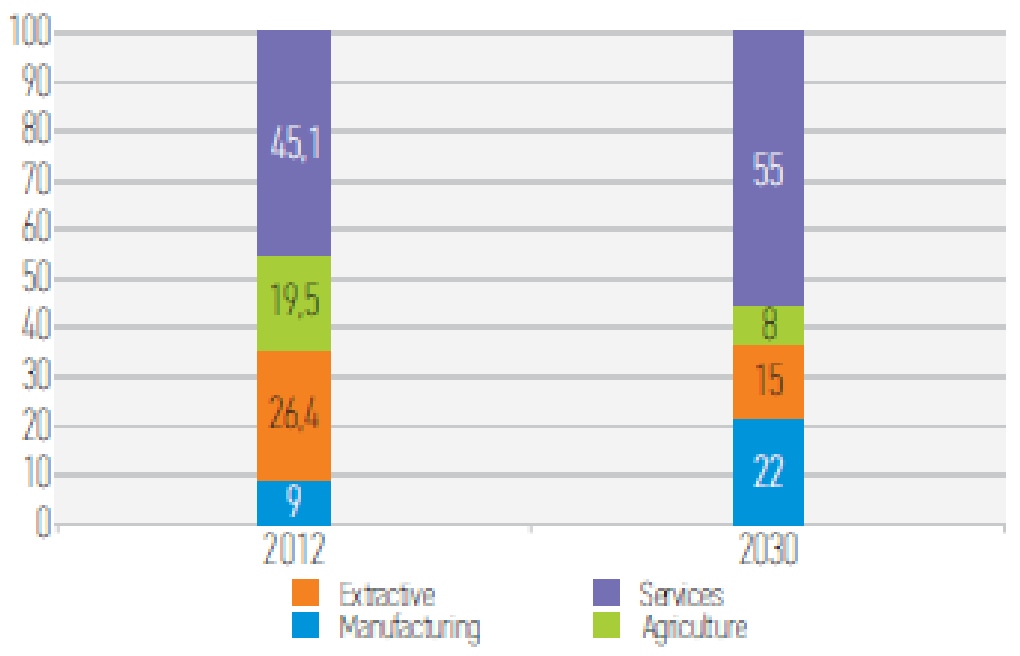

Fig. 2. Uzbekistan GDP composition by sector in 2012 (left) and target for 2030 (right) [2]. 
rates at $7-8 \%$ per annum over the next years and a structural transformation of the economy in a number of directions is required. A sector worth of development efforts is manufacturing: its share in the country GDP was $9 \%$ in 2012 and has to increase up to $22 \%$ by 2030 to achieve the aforementioned target.

The digitalization technologies that are promoting the Industry 4.0 paradigm can boost the manufacturing development also in developing countries like Uzbekistan, thus leading to a sort of re-industrialization resulting in increased product quality and technological content, improved process performance and higher work quality.

Therefore, Industry 4.0 may play an important role for economy development and support Uzbekistan in achieving the desired target. However, despite the wide thematic coverage and the depth of elaboration of various aspects of Industry 4.0 in the research of European and American scientists, the Smart Manufacturing paradigm is not fully formed in Uzbek manufacturing systems yet. Some of the technology advances representing the basis for Industry 4.0 are already used in manufacturing systems of the country. Nonetheless, a systematic approach for Industry 4.0 has not been developed and additional research is necessary to support a comprehensive adoption of this paradigm adapted to the Uzbek cultural background. In particular, the definition of requirements for implementation, the development methods and models for implementing smart production are necessary.

Therefore, the goal of this study is to define the gaps between Uzbek manufacturing systems and Industry 4.0 requirements with particular concern for automobile industry. The remainder of this paper is organized as follows. In Section 2, the vision of Industry 4.0 concept and its requirements are shortly reviewed; further, the advanced technologies of the Smart manufacturing are presented. In Section 3, the current state of Uzbekistan automotive manufacturing technologies are defined, and the gaps with respect to Industry 4.0 requirements are presented. In section 4, some proposal will be given to transform towards Industry 4.0. Last, in Section 5 some conclusive remarks are presented.

\section{The Industry 4.0 paradigm}

According to [1] Industry 4.0 is considered as future of manufacturing enabled by application of advanced ICT tools at production level to bring new values and services for customers and organizations. This new paradigm also brings flexibility and quality to fulfill demands. The digitalization and virtualization are tools to bring end-to-end services throughout a product life cycle and in a cost effective way for customers.

A formal definition of industry 4.0 is defined in [3] as follows: "Industry 4.0 will involve the technical integration of CPS into manufacturing and logistics and the use of the Internet of Things and Services in industrial processes".

Many researchers in Europe believe that industry is at the beginning of a new revolution, considered as fourth industrial revolution. The concept of Industry 4.0 is based on the German government initiative that was adopted as part of the "The new HighTech Strategy Innovations for Germany" [4]. This new paradigm holds the promise of increased flexibility in manufacturing, mass customization, increased speed, better quality and improved productivity [5]. 
To capture these benefits, industries will need to adopt a number of new and innovative technological advances, which are considered as building blocks of the Industry $4.0[6]$.

These technologies can be grouped as follows, according to their effect on the production systems.

Increased Production Flexibility. The development of autonomous robots capable of quick configuration and human cooperation [7], and the development of additive manufacturing technologies enable to produce a huge variety of products in the same manufacturing process [8]. This capability is boosted by integrating the manufacturing operations, both from the internal point of view (e.g. logistics) and the external perspective (e.g. suppliers). These abilities make the company able to rapidly adopt the customer-supplier specifications, properly adapt the process and profitably produce even small batches.

Shortened time-to-market. With the implementation of advanced technologies of Industry 4.0, the production pace can be also improved. 3-D simulation, augmented and virtual reality of the manufacturing process [9], tools for virtual product development and automation systems for production can reduce the time necessary for designing and manufacturing a product, this being able to quicker satisfy the demand of new products.

Increased Product Quality. Integrating product development through manufacturing chain with the help of Internet of Things (IoT) will lead to improve product quality [10]. This also directs decentralization of manufacturing process, enabling real-time decision-making. Embedded systems give the opportunity to implement total quality control practices, rather than using sampling to detect errors. Within the Industry 4.0 framework, products are provided with an embedded system (e.g. a RFID tag) since their early manufacturing stage of to collect data concerning its evolution over the production facility. This type of small, but critical, application of IoT in manufacturing results in reduced downtime, increased quality, reduced waste and less overall costs. This kind of products is known as Smart products. [10].

Increased Productivity. Process productivity can be increased through various effects of Industry 4.0 advanced technologies. For example, by using cloud-based software in manufacturing facilities data sharing across sites and company boundaries will increase. As a result, by advantage of cloud technologies and big data, performance of the manufacturing process can be improved, enabling more data-driven service for production systems [11].

Cybersecurity. One of the last technology advancements of Industry 4.0 is Cybersecurity. With increasing data generation across manufacturing systems, increasing connectivity, sharing data with partners in the value network will increase importance of the cybersecurity to protect critical industrial systems and lines from cyber-attacks [12]. 


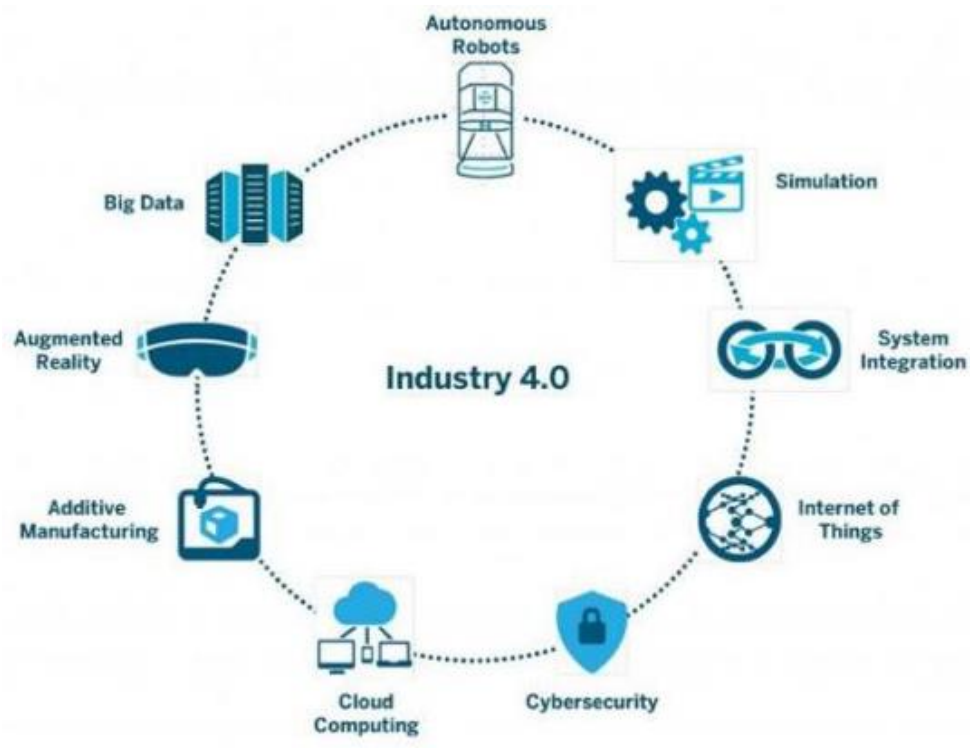

Fig. 3. The nine technologies enabling the Industry 4.0 paradigm [6].

\section{$3 \quad$ Industry 4.0 and the Uzbek automotive manufacturing system}

The Uzbek manufacturing environment is populated by companies in the fields of automotive, machinery, chemical industry and transportation services. However, according to the results of the Center of Economic Research [2], automotive is the most developed field and, thus, the driver of the country manufacturing.

The adoption of advanced technologies in Uzbek manufacturing has begun in the past years: additive manufacturing systems and autonomous robots have been implemented, as well as ICT solutions for simulation and systems integration have been adopted. Nevertheless, the deployment of such tools is still in its early stage and a wellestablished structure is necessary for further improvements. In the following, the current level of Industry 4.0 technology adoption is described and assessed through a scale ranging from 5 (high) to 1 (low). The evaluation of the Uzbek manufacturing systems led to design the graph in Fig. 4. A score equal to 5 has been assigned to technologies already implemented and highly experienced. Grade 4, is for technologies already implemented in industrial environments requiring further experience and training. Grade 3 is assigned to technologies investigated in research activities but not yet implemented in manufacturing systems. The score equal to 2 is assigned to technologies into an early stage of deployment: few research activities and/or prototypal installations have been done. Last, grade 1 denoted technologies in their infancy that are totally new for the country background. high level of research.

Autonomous robots. Manufacturers in Uzbekistan started to widely deploy robotic, flexible systems to tackle complex assignments. For example, in the vehicle assembly plant in Asaka [14] line-tracking robots have been already introduced in the assembly 
line. These robots are interconnected with the main production line and are in charge of picking and placing engines in the desired assembly position. A system of high-end sensors and control units has been installed to enable close and safe collaboration with both human operators and the surrounding production system.

As another example, the GM-Powertrain system consists of flexible production lines and automated machining systems for cylinder block, cylinder head and crankshaft manufacturing assisted by computers.

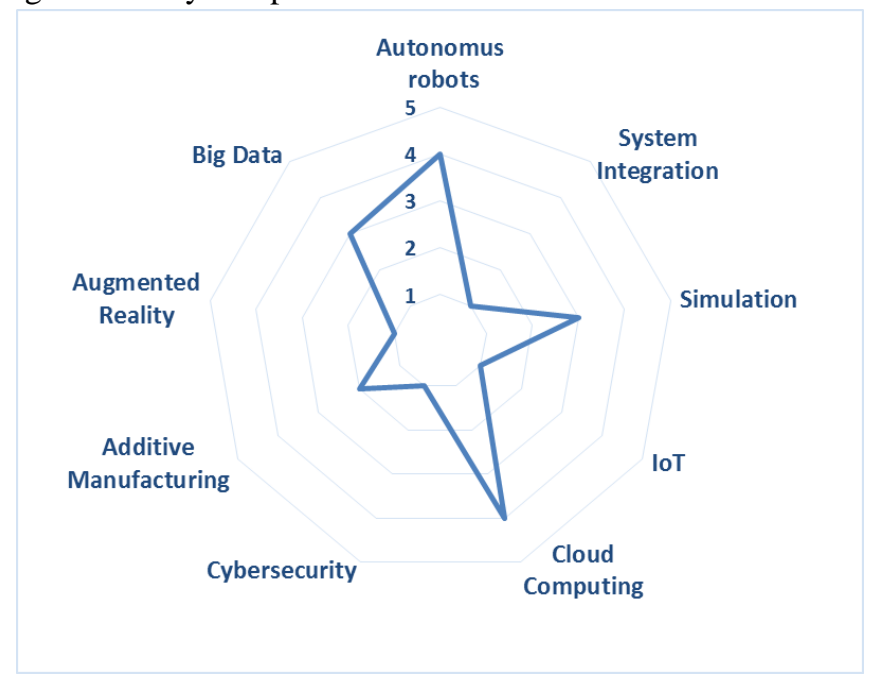

Fig. 4. Adoption level of technological advances into Uzbek automobile industry $[14,15,17]$

Big Data Analytics. Over the last 20 years' experience of automobile industry, data collection and analytics methods and technologies are increased. There are various methods and techniques for long-term strategic design decisions focusing on sites or the entire production process. Each supplier is using analytical tools and methodologies for improving product quality, equipment service level and energy saving. Even special department are organized for such specific analytics. For example, the most reasonable database for the current production control is the master data. Master data is used to execute the production process and quality control of the process. All changes of products characteristics, processes or resources in the manufacturing systems ultimately lead to changes in production master data.

Simulation. The effort in adopting ICT solutions has been mainly devoted to product design (CAD) and process design (CAM) tools. However, the spread of this technology should arise: simulation tools should be used to evaluate the performance of the manufacturing process in different operating scenarios and to identify the best strategy to react to possible issues, thus adapting on-the-fly the process and the supporting services (e.g. supply of components, logistics, maintenance). Nonetheless, the mere adoption of such tools is not sufficient for improving process performance: training programs must be developed to exploit as much as possible the advantages of such technologies. 
Additive manufacturing. The technology of 3-D printing has been adopted for a few years, mainly for rapid prototyping and to produce individual components only by research intuitions. In addition, this technology is also deployed in cooperation with reverse engineering technology of the small sized plastic vehicles part localization process. At this point academic site Tashkent Turin Polytechnic University [15] has great effort. Currently in the country, printing technology is more spread rather UV lasers and extrusion technologies.

Cloud Computing. A few companies are already using cloud-based software for some analytics applications, but analytics are more related to financial services than production. For example, the Cloud Computing SAP HANA technology began to be implemented into production process of GM-Powertrain. This experience mostly relies on logistics design and some analytical purposes.

In addition, Audit Company Deloitte in Uzbekistan implements SAP S/4HANA Finance for auditing some vehicle manufacturing companies like GM-Uzbekistan or GMPowertrain.

Furthermore, digital marketing framework is implemented in other sectors like textile engineering, banking systems, electric power industry of the country.

Internet of Things. The application of Internet of Things (IoT) in industrial environments is supposed to be one of the strongest enabling technologies of Industry 4.0. However, in order to implement IoT applications, efforts for ICT infrastructures must be spent.

In the last few years, the Uzbekistan government has strongly invested to develop ICT infrastructures to support IoT applications. Recent applications include, for example, monitoring of traffic congestion (based on Yandex, Google, and other maps services) as well as taxi booking or sharing. In a short time, these solutions changed the way to exploit mobility services in large cities such as Tashkent. Despite this diffusion in broad application, IoT is not yet applied in industrial environments: further efforts for educating technicians and operators to design, develop, implement and use this technology is necessary.

System Integration. Companies, suppliers and customers are still rarely linked over production process. In some cases, even the departments within the enterprise such as engineering, production, service, planning are not fully integrated along the value chain, through integrated IT systems. To overcome these problems, producers as well as suppliers must work to adapt new infrastructure within their production facilities and strengthen approaches to increase IT-related skills.

Cybersecurity. Since Uzbekistan is at first steps towards Industry 4.0, Cybersecurity is at infancy level. However, cybersecurity starting from 2018 is under governmental duty and it will be involved all resources for further developments. International forum on 2 February 2018 on Digitalization in Almaty (Kazakhstan) [16] can serve as first stage towards Cybersecurity of the Central Asian countries, including Uzbekistan.

Augmented reality. In Uzbekistan, Augmented reality (AR) is still in the early stages as in other developed countries. For example, in tourism industry authors of [17] developed android based mobile AR smartphone application which can act as a guide book for tourists of Uzbekistan. Conversely, the implementation of AR in industrial manufacturing in Uzbekistan would take some time since before AR we have to adapt 
our educational system to new technologies. Luckily, it will not take as long time as for developed countries since now information spreading very fast.

Table 1 represents the comparison between Uzbekistan today's factories and Industry 4.0 factories based on Technology and Production System

Table 1. Comparison of Uzbekistan today's factories and an Industry 4.0 factory.

\begin{tabular}{ccc}
\hline Today's Factories in Uzbekistan & Industry 4.0 Factory \\
Technology & $\begin{array}{c}\text { Precise Smart Sensors and } \\
\text { Fault detection, } \\
\text { Condition based monitoring } \\
\text { and Diagnostics } \\
\text { (quality and throughput) }\end{array}$ & $\begin{array}{c}\text { Self-aware, self-predictable, } \\
\text { self-compared, } \\
\text { predictive health monitoring, } \\
\text { remaining useful life moni- } \\
\text { toring }\end{array}$ \\
Production system & Based on Lean principles, \\
GMS systems & $\begin{array}{c}\text { Self-configured, decentralized, } \\
\text { integrated, self-organized, } \\
\text { cloud-based }\end{array}$ \\
\hline
\end{tabular}

\section{A roadmap for Industry 4.0 in Uzbekistan manufacturing}

Uzbekistan created a car industry from the ground up. Today, this industry produces more than 120,000 cars and their engines [20]. The production of new vehicle models that meet international standards concerning environmental impact, quality and safety is one of the main priorities of the Uzbekistan`s automotive car manufacturers. In order to increase the country export potential, create value chain along production facilities, increase manufacturing speed and productivity, and develop flexible manufacturing systems, the following measures must be further adopted in the next future.

Workforce qualification. To deal with the technologies shown in Fig. 3, high skilled workforce is necessary: besides competences on manufacturing, skills concerning process modelling, programming, simulation, and data analysis are required. Further, creativity for problem-solving and decision making will be increasingly necessary. According to an investigation promoted by the European Parliament, high skilled workforce is considered one of the core challenge of the future of manufacturing [19].

Therefore, to undertake the journey towards Industry 4.0, car manufacturers in Uzbekistan need to work on employee qualification. Industries need to define short, medium and long term strategies to address training of the already available employees, and manage vocational trainings.

Education and research activities. Institutions, research centers and manufacturing organizations must cooperate to adapt university programs and train workforce capable to work into an Industry 4.0 environment. Academic curricula must be updated to focus the attention on up-to-date information technologies and novel models for company management. 
Research is an essential condition for realizing the potential of the advanced technologies. In section 3, the adoption level of the Industry 4.0 enabling technologies has been discussed; however, for further development deeper analyses and research activities are required on each direction. Such efforts must also include frameworks and methodologies for technology adoption and deployment.

Adoption of cloud based software. Uzbek enterprises poorly adopted automation and IT tools, which allow to improve process planning and control, as well as to enhance the performance of each step of the manufacturing process. They do not make use of complex simulation tools or planning models, like elaborated above. In many cases, none of the employees of enterprises has experiences with such tools and therefore the possible advantages are often ignored.

As introduced in section 3, the SAP cloud software is mainly implemented for financial analysis. Nonetheless, to increase monitoring and control capabilities, further cloud tools must be adopted and mutually integrated for production control, supply chain control and other manufacturing related functions. This will lead to integrating the value chain across all the production process. However, to successfully use such tools, employees must be properly trained and educated. Therefore, SAP tool can be possible solution for production integration process.

Adoption of new manufacturing infrastructures. Innovative business models are willing to be introduced in Uzbek manufacturing systems. To achieve this result, integrated value chains must be realized between the departments of a company and, then, across suppliers and customers. This transformation requires high IT, data managing and analytics skills for decision-making.

Investments and National initiatives. Since the term Industry 4.0 was published, funding investments are the main critical challenge of this paradigm. To adopt and manage advanced technologies companies must dedicate great efforts, and need to be supported by institutions to meet the strategic national guidelines.

For this reason, on 2017, June $1^{\text {st }}$ the President of Uzbekistan signed a resolution entitled "On measures on further improving management and accelerated development of the automotive industry for 2017-2021". This program includes a list of investment projects, which will be implemented in the automobile industry [20].

\section{Conclusions}

The present work focused on development and adoption of Industry 4.0 paradigm in Uzbekistan automobile system and introduces the common vision of future manufacturing. The main concepts of the future manufacturing have been identified and current state of the Uzbekistan automobile manufacturing technologies in terms of Industry 4.0 requirements has been defined.

Some gaps between the current state of the automobile manufacturing sector and the requirements of future manufacturing environments have been highlighted and some lines to be adopted have been proposed. The research showed that manufacturing industries must invest in research and development activities as well as on staff qualification into the Industry 4.0 paradigm. 


\section{References}

1. Ateeq, K., Kalus, T.: A survey of current challenges in Manufacturing Industry and Preparation for Industry 4.0, Magdeburg Research and Competence Cluster, University of Magdeburg, Proceedings of the First International Scientific Conference "Intelligent Information Technologies for Industry" (IITI'16), Advances in Intelligent, Systems and Computing 450, DOI 10.1007/978-3-319-33609-1_2

2. Center for Economic Research: Uzbekistan towards 2030. A new social protection model for a changing economy and society, (2014). Available at: http://www.cer.uz/upload/iblock/6fd/bunxjnse\%20pwvc\%20en\%209.pdf. Last access: 2018/03/09

3. Kagermann, H., Helbig, J., Hellinger, A., Wahlster, W.: Recommendations for implementing the strategic initiative industrie 4.0: Securing the future of german manufacturing industry; final report of the industrie 4.0 working group (2013)

4. The German Federal Ministry of Education and Research: The new high-tech strategy innovations for Germany (2014). Available at: https://www.bmbf.de/pub/HTS_Broschuere_eng.pdf.

5. Burke, R., Mussomeli, A., Laaper, S.:The smart factory. Responsive, adaptive, connected manufacturing. Deloitte University Press (2017).

6. Gerbert, P., Lorenz, M., Rüßmann, M., Waldner, M., Justus, J., Engel, P., Harnisch, M.: Industry 4.0: The future of productivity and growth in manufacturing industries. BCG Group (2015). Available at: https://www.bcg.com/it-it/publications/2015/engineered_products_project_business_industry_4_future_productivity_growth_manufacturing_industries.aspx

7. Thoben, K.D., Wiesner, S., Wuest, T.: "Industrie 4.0" and Smart Manufacturing -A review of research issues and application examples. International Journal of Automation Technology 11(1), 4-16 (2017).

8. Ford, S., Despeisse, M.: Additive manufacturing and sustainability: an exploratory study of the advantages and challenges. Journal of Cleaner Production 137, 1573-1587 (2016).

9. Mourtsiz, D., Doukas, M., Berdinaki, D.: Simulation in manufacturing: Review and challenges. Procedia CIRP 25, 213-229 (2014).

10. Onder, O., Gupta, S.: Quality management in product recovery using Internet of Things: An optimization approach. Computers in Industry 65(3), 491-504 (2014).

11. Qin, J., Liu, Y., Grosvenor, R.: A categorical framework of manufacturing for Industry 4.0 and beyond. Procedia CIRP 52, 173-178 (2016).

12. Zong, R., Klotz, E., Newman, S.: Intelligent manufacturing in the context of Industry 4.0: a review. Engineering 3(5), 616-630 (2017).

13. Hutchins, M.J., Bhinge, R., Micali, M.K., Robinson, S.L., Sutherland, J.W., Dornfeld, D.: Framework for identifying cybersecurity risk in manufacturing. Procedia Manufacturing 1, 47-63 (2015).

14. http://uzavtosanoat.uz/en/JSC-GM-UZBEKISTAN.html.

15. https://polito.uz/index.php?lang=en.

16. http://kazakh-tv.kz/2015en/view/news_kazakhstan/page_190699_

17. https://www.morebooks.shop/store/us/book/mobile-ar-application-for-tourism-industry-ofuzbekistan/isbn/978-3-330-51698-4

18. https://www.azernews.az/region/125414.html

19. R. Davies: Industry 4.0 Digitalization for productivity and growth (2015).

20. https://www.uzdaily.com/articles-id-39812.htm 